\title{
El desplazamiento forzado: un reto para la transformación del quehacer docente ${ }^{*}$
}

\section{Forced displacement: a challenge for the transformation of the teaching task}

\author{
Tatiana Melissa Muñoz Cáceres ${ }^{1}$
}

Para citar este artículo: Muñoz, T. M. (2018). El desplazamiento forzado: un reto para la transformación del quehacer docente. Infancias Imágenes, 18(1), 132-141

\section{Resumen}

Este artículo es el resultado de la participación como joven investigadora en el proyecto "Incidencia del desplazamiento forzado en las prácticas pedagógicas de primer ciclo de dos instituciones educativas de Bogotá". En la misma se propuso como objetivo analizar estas prácticas, planteando como pregunta problema: ¿cuál es la incidencia del desplazamiento forzado en las prácticas pedagógicas de primer ciclo de dos instituciones educativas de las localidades de Bosa y Ciudad Bolívar en Bogotá? Se empleó un enfoque cualitativo de corte etnográfico, haciendo uso de técnicas como la entrevista, la antología de historias y los talleres dirigidos a estudiantes de transición, primero y segundo grado, al igual que a los docentes titulares. Como categorías de análisis se establecieron: las prácticas pedagógicas, el desplazamiento forzado y las relaciones interpersonales. Los hallazgos y las conclusiones están centrados en dichos aspectos, haciendo énfasis en la importancia de repensar y replantear las prácticas pedagógicas.

Palabras clave: migración, práctica pedagógica, relaciones interpersonales.
Recibido: 30-abril-2018 / Aprobado: 16-noviembre-2018

\begin{abstract}
Albstract:
This paper is the outcome of the participation as a young researcher in the project "Incidence of forced displacement in the first cycle teaching practices of two educational institutions in Bogotá." The aim of this study was to analyze these practices, posing as a problem question: What is the incidence of forced displacement in the first cycle teaching practices of two educational institutions in Bosa and Ciudad Bolívar, in Bogotá? A qualitative ethnographic approach was used, using techniques such as interview, storytelling anthologies and workshops aimed at preschoolers and grade One and Two students, as well as regular teachers. Categories of analysis were established, such as: teaching practices, forced displacement and interpersonal relations. The findings and conclusions focus on these aspects, emphasizing the importance of rethinking and reposing teaching practices.
\end{abstract}

Keywords: migration, teaching practices, interpersonal relationships.

\footnotetext{
* Investigación en curso.

1 Licenciada en Pedagogía Infantil, Fundación Universitaria Los Libertadores. Joven investigadora. Correo electrónico: tmmunozc@libertadores. edu.co
} 


\section{Introducción}

Desde la década de 1940, Colombia se ha visto inmersa en un panorama de violencia protagonizado por actores del conflicto armado (guerrilla, paramilitares, fuerzas estatales) y su desarrollo a través de diferentes etapas diferenciadas por su condición geográfica, intensidad, marco político, entre otros. De esta manera, el desplazamiento forzado es consecuencia directa y visible de la proliferación de grupos armados, así como constituyente de la violación múltiple de los derechos humanos.

El desplazamiento forzado como estado de movilidad poblacional, configura panoramas de adaptaciones y cambios complejos no faltos de tensiones y conflictividad por las condiciones de desigualdad en las que se produce. Ello induce al sujeto que lo vive a ser portador de nuevas producciones simbólicas y de construcción de identidades, relaciones, formas de interacción y miradas diferenciadas de un otro, también portador de estas características que, aunque diferentes, también lo configuran como sujeto.

Estos encuentros e interacciones, llevados a cabo en la cotidianidad, permean nuevas elaboraciones culturales del otro, creando las similitudes y diferencias que los unen o los separan y que permiten el establecimiento de relaciones asimétricas en las que unos desean conservar su supremacía y los otros obtener reconocimiento. Razón por la cual la persona desplazada debe enfrentar la aceptación o el rechazo de la población receptora, desembocando en una nueva configuración de sujeto (Correa de Andreis, Palacio, Jiménez y Díaz, 2009).

Este sujeto que el desplazamiento ha producido es, en palabras de Albán (2012):

Un nuevo sujeto que es el resultado del desarraigo territorial y cultural, del terror de la guerra, del miedo por las amenazas, de los intereses ajenos a sus proyectos de vida colectivos e individuales, de la injerencia y presencia de actores armados externos a sus lugares de origen, de la utilización indiscriminada de la fuerza, de la vejación y la humillación, del avance arrollador de intereses y capitales que pugnan por ocupar sus territorios. (p. 59)

Este nuevo sujeto converge entonces en la misma realidad que el receptor, quien forma parte de la comunidad que recibe a la población desplazada que, aunque muchas veces ajeno a la realidad del primero, posee también un sinfín de particularidades y características. Lo anterior hace necesario en ambos sujetos, su reconocimiento y potenciación como portadores de cualidades y habilidades que permean el desarrollo de su individualidad, de la socialización y la toma de decisiones propias y colectivas.

Frente a estas aseveraciones y características generales de la violencia y desplazamiento que vive nuestro país, prima caracterizar la situación cultural y las relaciones interpersonales de la población desplazada y receptora; ubicando así mismo la relación con la escuela y su papel como garante de derechos y propiciadora en el desarrollo de aptitudes, capacidades y relaciones.

Por esta razón la escuela se convierte en un escenario de protección "que entiende y permite que los niños y niñas sean sujetos de derecho, como el de participar, a no ser discriminados, a que sus preocupaciones, anhelos y opiniones sean escuchadas y tenidas en cuenta" (Acnur, Corporación Acción Legal y Universidad Pedagógica Nacional, 2004, p. 11). Así pues, bajo ninguna circunstancia la escuela puede renunciar a su papel como agente social en la formación de sujetos autónomos, de derechos, capaces de ir creando el rumbo de sus vidas para satisfacer sus necesidades vitales, críticos, reflexivos y capaces de transformar su entorno en beneficio no solo propio, sino también colectivo.

Para lograr estos objetivos, la escuela debe propender por el desarrollo y la implementación de estrategias educativas encaminadas a la recuperación de la identidad y del sujeto que ha ido perdiendo su valor, a la resignificación del entorno, la recuperación de la confianza y la continuidad del ciclo vital, al igual que propiciar espacios de conocimiento y respeto por las tradiciones y culturas que el otro ya posee.

Entonces, el docente inmerso en los diferentes contextos escolares, se ve obligado a repensar las antiguas prácticas de educación tradicional, ocupadas de la transmisión de conocimiento y de "enseñar" a obedecer, hacia una mirada inclusiva e intercultural, centrada desde el contexto, transformando su intención y logrando dar al sujeto una 
identidad distinta a ser un otro diferente pues la percepción que se construye en el entorno receptor y en la escuela, es de estigmatización, criminalización y estrecha vinculación con los actores armados del conflicto.

Para dar importancia a este tipo de acciones emprendidas por maestros y maestras que dan respuesta a estas complejidades, el trabajo investigativo tomó como referente a las instituciones: colegio Carlos Albán Holguín IED sede $\mathrm{C}$ de la localidad de Bosa y el colegio La Estancia San Isidro Labrador IED sede primaria de la localidad de Ciudad Bolívar, y a su vez específicamente como muestra a los estudiantes de los grados transición, primero y segundo y sus respectivos directores de curso. Según informes registrados por la UAID (Unidad de Atención Integral al Desplazado), son estas localidades las que reciben el mayor número de población desplazada con un $10.3 \%$ y $26.2 \%$ respectivamente (Acnur, 2003). Estas zonas presentan altos porcentajes de población en condiciones de miseria y de pobreza, aspectos que agudizan la crisis en estas localidades que, junto con los procesos migratorios, marcan una dinámica de intempestivo crecimiento urbano que desemboca en "una compleja conflictividad social pero también en una multiplicidad de presencias culturales y étnicas" (Albán, 2012, p. 57).

Los elementos aludidos en párrafos anteriores, permitieron plantear la siguiente pregunta problema como eje de la reflexión propia de este estudio: ¿cuál es la incidencia del desplazamiento forzado en las prácticas pedagógicas de primer ciclo de dos instituciones educativas de las localidades de Bosa y Ciudad Bolívar en Bogotá?

Además, el estudio estableció tres categorías de análisis: desplazamiento forzado, prácticas pedagógicas y relaciones interpersonales, las cuales constituyeron el eje central de la investigación.

La metodología que se puso en funcionamiento en el proyecto corresponde al estudio cualitativo de corte etnográfico. De acuerdo con Rodríguez, Gil y García (1996), la investigación cualitativa puede entenderse como:

El proceso que estudia la realidad en su contexto natural, tal y como sucede, intentando sacar sentido de, o interpretar los fenómenos de acuerdo con los significados que tienen para las personas implicadas. La investigación cualitativa implica la utilización y recogida de una gran variedad de materiales (entrevista, experiencia personal, historias de vida, observaciones, textos históricos, imágenes, sonidos), que describen la rutina, las situaciones problemáticas y los significados en la vida de las personas. (p.10)

Por su parte, Giddens (2007) define el enfoque etnográfico como:

El estudio directo de personas o grupos durante un cierto periodo, utilizando la observación participante o las entrevistas para conocer su comportamiento social, registrando una imagen realista y fiel del grupo estudiado; el trabajo de campo resulta ser una herramienta imprescindible. (p. 27)

Se aplicaron tres instrumentos de investigación: la entrevista semiestructurada desde el ámbito cualitativo a los directores de grupo de los grados transición, primero y segundo de ambas instituciones educativas; los diarios de campo desarrollados por semilleristas; y talleres de literatura, narrativa y pintura, todos estos para dar cuenta de las prácticas pedagógicas desarrolladas por los docentes frente a las situaciones de desplazamiento forzado presentadas en el aula, el reconocimiento de los imaginarios frente al mismo y la identificación y caracterización de las relaciones interpersonales entre los actores educativos.

\section{Desplazamiento forzado: una realidad ignorada}

El desplazamiento forzado es definido por Ramírez (2014) como "el escape de una realidad difícil de sobrellevar por conflictos bélicos, de violencia, pobreza o marginación, consecuencias de la desigualdad local y global" (p. 34), es un proceso migratorio definido por la interacción de dos dinámicas principales: la expulsión y la movilización, acciones que afectan la manera cómo los actores inmersos en ellas se relacionan consigo mismos, con los demás y con el nuevo entorno.

Esta migración tiene un alto impacto personal y social tanto en las comunidades de procedencia como en las de acogida, pues representa un 
desarraigo a nivel físico, social y cultural. "La migración es el resultado de una desigualdad generada a partir de la inclusión de algunos y la exclusión de otros para quienes la movilidad es una opción en la búsqueda de mejores condiciones de vida determinada por la precariedad de sus lugares de origen" (Ramírez, 2014, p. 63).

Al hablar de desplazamiento forzado en el marco de la investigación, es necesario recordar que se está haciendo referencia a las características propias de la institución que permiten conocer la incidencia del mismo en las prácticas pedagógicas de los docentes.

Frente a esto, es evidente que los maestros tienen claridad sobre el concepto de desplazamiento forzado y la población víctima de esta situación que se encuentra en sus aulas de clase, pues docentes del colegio La Estancia San Isidro Labrador IED, en una de las entrevistas realizadas lo definen como:

Es cuando las familias tienen que salir de sus casas forzosamente.

Hablando entonces del contexto específico del aula, aseguran que como los casos de niños y niñas víctimas de desplazamiento forzado, no se hacen públicos ni evidentes dentro de la comunidad educativa, el contacto se hace sin contratiempos. El problema radica en la forma en que este estudiante se relaciona con los demás y las características de las situaciones que ha vivido, lo identifican ahora como sujeto: escasa comunicación verbal y dificultad en el contacto y la relación con el otro, consecuencia de una crisis identitaria a causa de la inserción repentina en un medio cultural nuevo y por ende distinto.

Estas afirmaciones son sustentadas por una docente del colegio Carlos Albán Holguín IED cuando dice:

Esos casos no se hacen a voz pública, sino que son casos que llegan y solo los sabe la docente y no se comunican. Pero estos niños sí son un poco reacios, de pronto al contacto con los otros niños. Es un niño ensimismado, tímido, que le cuesta relacionarse [...] muy tímido para relacionarse con sus compañeros; generalmente con la parte de comunicación verbal muy escasa.
Aseveraciones que dejan ver no solo la situación de los niños y niñas desplazados que llegan a las aulas, sino de los niños y niñas que se han visto afectados por estas dificultades a lo largo de los años en nuestro país. En palabras del Centro Nacional de Memoria Histórica:

Se pone en evidencia uno de los aspectos más dramáticos del conflicto y la violencia sobre el futuro de la sociedad colombiana: el desproporcionado impacto, cuantitativo y cualitativo, que ha tenido el desplazamiento forzado en las personas menores de edad. Resulta preocupante que desde edades tempranas, principalmente entre la primera infancia (0-5 años) y la niñez (6-12 años), la población sea sometida a una serie de daños en su integridad mental y física. (2015, p. 416)

A estos aspectos se suma el hecho de tener que enfrentarse constantemente a una variedad de dificultades que incluyen la pobreza, problemas en los procesos de aprendizaje, falta de acceso a la asistencia médica, trabajo infantil y un sinfín de violaciones a sus derechos, acumulando desde edades tempranas la experiencia del dolor, del hambre, de las culturas desconocidas y de los recuerdos que gritan en el silencio.

Además, los niños y niñas víctimas de desplazamiento sufren un deterioro de su desarrollo integral y armónico, así como una amenaza a su derecho a ser protegidos contra toda forma de maltrato, explotación, abandono y discriminación. Esto supone un obstáculo para que desarrollen sus capacidades y logren participación política y social en su entorno, pues en sus hogares se transmite la sensación de peligro y amenaza que viene con su círculo familiar (Centro Nacional de Memoria Histórica, 2015).

Por esta razón, es importante que la escuela como agente indispensable de la comunidad receptora centre su interés en las posibilidades que debe generar para que los sujetos víctimas del conflicto armado construyan nuevas identidades y subjetividades a partir del reconocimiento de sus capacidades, potencialidades y talentos que permeen tanto en lo individual como con respecto a sus relaciones, a través de una posible canalización de la atención a expresiones que se alejen de la victimización 
y estigmatización que se vienen generando, pues como lo asegura el Centro Nacional de Memoria Histórica "la reparación integral a esta población supone reconocer la transmisión generacional de los daños causados. Ese reconocimiento demanda a su vez que no sean revictimizados en los lugares en que fueron forzados a reubicarse" (2015, p. 418).

Teniendo en cuenta los aspectos descritos anteriormente frente a las circunstancias a las que se encuentran expuestos los niños y niñas en situación de desplazamiento, ¿qué tan asertivo es que se niegue su condición para evitar ser blanco de exclusión? Si bien es cierto que la comunidad receptora y varios sectores de la sociedad tienden a estigmatizarlos, el hecho de negar el sitio de procedencia para no ser señalados, hace que olviden sus creencias y arraigos culturales (Acnur, Corporación Acción Legal y Universidad Pedagógica Nacional, 2004), perdiendo su identidad y convirtiéndoles en sujetos al que se les vulneran sus derechos y funciones dentro de la estructura escolar y social.

Estos aspectos a su vez limitan los aprendizajes y el desarrollo integral de sus competencias, pues "se ha comprobado que cualquier modificación de conductas por cambios inesperados en los hábitos de vida, trastornan el modo de ser y de pensar de las personas" (Acnur, Corporación Acción Legal y Universidad Pedagógica Nacional, 2004, p. 92). Los sujetos víctimas de desplazamiento, especialmente jóvenes y niños, al ser estigmatizados como población violenta y difícil, quedan marcados negativamente para enfrentar su vida de adultos, pues la edad en la que se forman los valores, las costumbres y las creencias ha sido rebasada por un sinfín de emociones, recuerdos y acciones que forman parte de la respuesta positiva o negativa frente a hechos actuales de su vida.

Por su parte, otro de los aspectos preocupantes y que tiende a pasar a un segundo plano es el accionar de las instituciones desde su proyecto educativo institucional (PEI) frente a las necesidades de los niños y niñas en situación de desplazamiento; pues, según lo expuesto por una docente del Colegio Carlos Albán Holguín IED:

En el momento no hay proyectos para la inclusión de niños y niñas en situación de desplazamiento. Sí hay ocasiones en que nos mandan a preguntar casos de niños de alto riesgo de vulnerabilidad, pero que yo vea así dentro de la institución, no.

Así mismo, una maestra del colegio La Estancia San Isidro Labrador IED asegura que:

Hay un proyecto en la sede A, pero nosotros no estamos muy vinculados a ese proyecto porque nosotros somos como aparte. A nosotros no nos han dicho como tal vincúlense a este.

Como resultado de estas afirmaciones, se puede ver que los centros educativos no plantean ni desarrollan estrategias concretas para la inclusión de esta población, dejando así expuesto el poco conocimiento e identificación frente a la realidad de las aulas, sus necesidades e intereses, así como la falta de espacios de reflexión y evaluación continuos del saber, hacer y ser del maestro en torno a su quehacer pedagógico.

Cabe resaltar, entonces, la importancia de una visión de infancia inmersa en situaciones de conflicto, como víctimas con un fuerte e intenso deseo de verse inmersos en labores de reinserción tanto educativas como sociales que permeen nuevas formas de relacionarse y auto-reconocerse a través de la apertura de espacios de reflexión y sensibilización con miras hacia la reconstrucción de la sociedad, transformando la percepción de que el desplazamiento debe ser solucionado a través de programas asistenciales y resaltando que "es un imperativo ético del Estado y de la sociedad priorizar los derechos de la infancia, aún en medio de la guerra" (Jiménez, 2012, p. 157).

\section{Práctica pedagógica en torno al desplazamiento forzado}

Frente a esta categoría de análisis, la docente de grado segundo del colegio La Estancia San Isidro Labrador IED asegura que:

El desplazamiento forzado incide en la práctica pedagógica en la manera en que permite crear más estrategias para poder vincular a los niños de otra manera, vincular a la familia para que se acerque más a la institución y logren relacionarse mejor con sus compañeros. 
Estas estrategias deben ser planteadas teniendo en cuenta la emergencia social que sufre la escuela, donde el desplazamiento se encuentra dentro de la misma. Estas deben percatarse de que el proceso de inclusión e integración de estudiantes, padres y madres de familia y los propios maestros a la vida de la comunidad escolar solo es posible en la medida en que las formas mediante las cuales se manifiesta el desarraigo sean valoradas como profundas necesidades vitales que han sido brutalmente cortadas de la historia y biografía de cada niño y niña víctima del desplazamiento (Restrepo, 1999).

Esto implica una práctica pedagógica basada en el reconocimiento del otro, en la cual la diferencia cobra valor en la consecución de la autonomía de los sujetos y la construcción de sus identidades. A su vez, estas prácticas y los maestros mismos desde su quehacer pedagógico necesitan reflexionar y accionar frente a las consecuencias emocionales, cognitivas y relacionales que genera en los estudiantes las situaciones de conflicto armado y desplazamiento; entendiendo el impacto que genera en estos, específicamente en el contexto escolar, y logrando responder a sus necesidades.

Frente a estas afirmaciones valdría la pena preguntarse: ¿a qué se hace referencia cuando se habla de prácticas pedagógicas? Se hace necesario retomar la definición dada por Contreras y Contreras (2012), quienes se refieren a estas como una acción dinámica y compleja, que debe responder a las necesidades educativas de la sociedad actual; ello requiere que estén en correspondencia con las necesidades e intereses de los educandos, del contexto, de los avances de la ciencia y la tecnología y con las políticas educativas del país.

Es posible entonces ubicar la práctica pedagógica como un amplio concepto que también abarca, en palabras de Zuluaga (1999):

Un sistema de relaciones que emerge en el campo educativo, articulando modelos pedagógicos con los cuales se orienta la enseñanza, la diversidad de conceptos, de campos heterogéneos de conocimiento, los discursos teóricos que fundamentan los saberes pedagógicos y el contexto, de tal manera que esta se configure como una noción analizadora del desplazamiento forzado en el marco de la escuela, la enseñanza, el maestro, el alumno y la relación pedagógica, en tanto este fenómeno desborda la escuela, el aula; la enseñanza y requiere ser leído desde una categoría, con la amplitud suficiente para pensarla, puesto que en la práctica pedagógica se articula la institución, el sujeto y el discurso, lo que permite circular, entre la interioridad y exterioridad de la escuela. (p. 18)

La práctica pedagógica puede ser vista como una dinámica de ser, saber y hacer que tanto el contexto como las necesidades de los estudiantes le conceden al maestro para transformar el entorno social desde la institución. Así pues, el docente debe hacerse consciente de su papel dentro del proceso educativo y dentro de la formación de los estudiantes.

Por este motivo, Pérez-Juste (2010) asegura que el docente se debe caracterizar por ser un artista intelectual que, a partir del desarrollo de la sabiduría que da la experiencia, crea e innova en su práctica cotidiana. En este sentido, se define la práctica pedagógica como una de las características de la enseñanza, que el mismo docente construye en su quehacer cotidiano.

Frente a las prácticas pedagógicas de los docentes de las instituciones objeto de estudio, se resalta su interés por trabajar con la individualidad y particularidad de cada estudiante y en la creación de estrategias que involucren a todos en las actividades del aula. Como expone una docente del colegio Carlos Albán Holguín IED:

Bueno, yo creo que cada una de las actividades que se realizan en el aula, se realizan pensando en la individualidad de cada niño. Independientemente de la problemática que tengan, porque cada niño es un mundo diferente y cada niño trae su problemática.

Así mismo, una docente del colegio La Estancia San Isidro Labrador IED expresa que:

Lo que nosotros manejamos aquí es que pues todos son bien recibidos, todos son tratados por igual. Ninguno es diferente, ni siquiera el niño que tiene necesidades es diferente, todos se tratan por igual, a todos se les pide lo mismo. Todos son recibidos con los brazos abiertos, todos se tratan de la misma 
manera, no hay preferencias porque vengan de otra ciudad o porque ya estén aquí.

Estas afirmaciones permiten reflexionar sobre el papel de la escuela como escenario incluyente. Aunque permite pensar y dinamizar un marco de educación para todos y las mejoras de las condiciones en las que se presenta la oferta educativa para los más vulnerables, vale la pena preguntarse si ¿ todos los tipos de población necesitan la misma atención?

Al respecto, la OEI (2009) resalta que:

La buena práctica inclusiva debe entenderse como una actuación "situada", que adquiere sentido y es viable a partir de una realidad concreta, de unos condicionantes estructurales que la hacen única e irrepetible. No hay buenas prácticas ideales sino que dependen del contexto en el que se desarrollan. (p. 5)

Así es como la presencia de estudiantes con distintas identidades y características constituye un desafío para el sistema educativo que necesita dar respuestas adecuadas y acertadas a niños, niñas y jóvenes con experiencias y niveles educativos heterogéneos e historias y circunstancias diferentes.

El reto que esto involucra consiste en atender una diversidad que llega al aula, desde una perspectiva de derechos, que ya han venido siendo vulnerados, partiendo de principios de flexibilidad y heterogeneidad, tomando conciencia del ahora, trabajando sobre sus necesidades y problemáticas más apremiantes para desembocar así todo un proceso de creación curricular, contrario a una propuesta enajenada y ciega, que de ninguna manera responde a las urgencias de dicha transformación social (Díaz y Sarmento, 2011).

\section{Relaciones interpersonales: del ellos al nosotros}

Las relaciones interpersonales, según Bisquerra "son interacciones recíprocas entre dos o más personas" (2003, p. 23). Se trata entonces de un sinfín de relaciones sociales que, como tales, implican el intercambio de formas de sentir, necesidades, intereses y afectos. Por este motivo, se considera al sujeto como un ser eminentemente social, que desde el momento de su nacimiento establece relaciones con otros: la familia, como primer agente de socialización, permite al niño las primeras interacciones sociales y le prepara para asumir el reto de enfrentarse a otros escenarios; y la escuela como segundo agente, es el espacio en el cual los niños y las niñas se relacionan con sus pares y otros adultos, reconocen las reglas y normas que les permitirán interactuar en otros contextos.

En el caso de las instituciones objeto de estudio, los actores expresan que las relaciones entre estudiantes se encuentran mediadas por agresiones físicas, verbales y de exclusión social, resultado de las carencias afectivas y relaciones familiares no asertivas de las que, según maestros, son víctimas los niños y niñas. Tal como lo afirma una docente del colegio Carlos Albán Holguín IED:

Las relaciones son un poco difíciles, por la misma problemática que se presenta a nivel familiar. Hay agresión familiar y eso se refleja aquí. Les cuesta mucho pedir perdón, porque generalmente en su contexto no lo hay.

Así mismo, en algunos de los talleres realizados con los estudiantes de grado segundo del colegio La Estancia San Isidro Labrador IED, en el que se les pide responder a algunas preguntas y representar de forma teatral situaciones que viven diariamente en el aula, resaltan expresiones como: "algunos de mis compañeros me empujan" y "acá no tengo muchos amigos". Así mismo, en su mayoría realizan dramatizaciones basadas en agresiones físicas y verbales entre compañeros.

Estas situaciones hacen necesario que los encuentros de la vida escolar trasciendan las relaciones meramente burocráticas y se establezca una verdadera comunicación, en la que el maestro sea garante de encuentros significativos.

La escuela es, entonces, el lugar donde se construyen las relaciones y se complementan otras edificadas fuera de la misma. "Es el entorno que más contribuye en la incorporación de límites y normas, procesos que más que un aprendizaje resultado de la enseñanza, surgen como algo que se construye a partir de la interacción con los pares" (Bello, Díaz y Rincón, 2016, p. 147). 
Por eso, este escenario de interculturalidad necesita trabajar sobre procesos mediados por una concepción de relacionamiento que propendan por erradicar todo tipo de prácticas y formas de exclusión y que logre la construcción de espacios de diálogo que permeen el reconocimiento y respeto por la diversidad y la diferencia; dejando de lado los antiguos modelos tradicionales de educación que han sido y son insuficientes para responder a las nuevas configuraciones de sociedad, escuela y sujeto.

Por lo que se refiere a las relaciones interpersonales entre estudiantes y docentes, en común acuerdo entre los maestros entrevistados y los alumnos a través de los talleres realizados, se expresa que estas se caracterizan por la paciencia, el amor y el respeto. En palabras de una profesora del colegio Carlos Albán Holguín IED:

"Los niños tienen carencia de afecto, que se nota en el hogar, entonces ellos buscan aquí ese afecto en las docentes".

Los alumnos como seres individuales, únicos, diferentes, con potencialidades, con necesidades y con carencias distintas, no solo participan y se desarrollan cognitivamente, sino que también lo hacen de forma afectiva y valorativa. Las características presentadas antes como eje de las relaciones maestro-estudiante no solo crean vínculos, sino que permean los procesos de enseñanza-aprendizaje.

Dicho de otra manera, el profesor, a través del cómo de su quehacer docente, propicia en sus estudiantes el desarrollo de determinados vínculos. Por eso este quehacer cobra una importancia especial, no solo en función de los aprendizajes académicos, sino también en el aprendizaje de procesos de socialización que accionará el alumno a través de las relaciones interpersonales que desarrolle en el contexto en que se encuentre. La acción docente debe trascender el ámbito de las relaciones de clase y proyectarse en las relaciones hacia la sociedad (Bohoslavshy, 1986).

La comunicación y la interacción como procesos básicos para la construcción de la vida en sociedad necesitan ser vistos como mecanismos esenciales activadores del diálogo y la convivencia a través del establecimiento de relaciones con otros, yendo de un ellos a un nosotros. Este es un proceso básico para la adquisición de una capacidad reflexiva para verse a sí mismo, dando sentido a la realidad que lo rodea y para una verdadera construcción de una vida en sociedad.

\section{Conclusiones}

La realidad de la escuela está indiscutiblemente marcada por la dinámica que se genera entre los mismos miembros de la comunidad educativa, siendo indispensable conocer los elementos significativos que la conforman. Para ello es esencial hacer del acto educativo un proceso reflexivo, sistemático e investigativo que permita entender y reconocer las falencias que se presentan en el contexto escolar y de esta forma atenderlas en pro de la formación integral de los estudiantes. Esto, teniendo en cuenta la participación de la familia en el proceso, para lograr así fortalecer la construcción de identidad, relaciones e interacciones que contribuyan al reconocimiento y asertivo accionar de los sujetos.

Así pues, las prácticas docentes que, aunque dan prioridad a procesos de inclusión generales, necesitan ser replanteadas hacia las características propias que el desplazamiento forzado y los sujetos víctimas del mismo que Ilegan al aula de clase poseen frente a afectaciones y necesidades sociales, educativas y emocionales producto de las situaciones y experiencias vividas, hablando de la resiliencia como un camino posible, para que logren desarrollar habilidades reflexivas, actitudes y estrategias de comunicación y organización que les permitan la reconstrucción de sus proyectos de vida.

Repensar lo institucional y replantear las prácticas pedagógicas que trabajan con las diferentes circunstancias del desplazamiento es la clave. Pues es la escuela uno de los escenarios principales donde se logra asumir un verdadero compromiso con esta población. Por esto, en todas las instituciones, en especial en las formadoras de maestros, el currículo debe estar impregnado por la problemática social del desplazado, permitiendo que se creen prácticas que respondan a las características pedagógicas y necesidades de los sujetos en situación de desplazamiento. 
Hablar de una formación del docente, aún desde la academia, permite hacer del mismo un sujeto crítico y reflexivo de su quehacer pedagógico: planteando sus prácticas desde una perspectiva de derechos, incentivando la creación de salidas no espontáneas ni momentáneas, sino que posesionen a la escuela como escenario de posibilidades y a la práctica pedagógica como una construcción no unidireccional, en donde el conocimiento se recree en el contexto social, dando un nuevo sentido a la vida del sujeto.

Esta formación debe comprender no solo el desarrollo de capacidades y competencias propias de la disciplina sino, además, las dimensiones personales e investigativas basadas en la comprensión de la realidad social y la necesidad de realizar una reflexión crítica de su acción pedagógica en pro de transformar el aula que es el escenario de sus actuaciones. Esto sin dejar de lado el proceso continuo de aprender de la experiencia y su compromiso con el desarrollo de una sociedad democrática e inclusiva. En palabras de Kemmis "la práctica de la educación es una forma de poder, una fuerza dinámica tanto para la continuidad como para el cambio social que, aunque compartida e impuesta por otras personas, sigue estando en gran parte en manos de los maestros" (2002, p. 17).

Aunque la garantía de derechos es competencia del Estado, es indispensable que los maestros y docentes en formación cuenten con procesos de cualificación y seguimiento en temas de conflicto armado y, como consecuencia del mismo, el desplazamiento forzado, trabajando en sus prácticas pedagógicas y desde allí, aportar a construcciones colectivas de paz y de vínculos afectivos que permitan el reconocimiento de las problemáticas mencionadas y el accionar pedagógico en torno a las mismas.

Cabe resaltar que para futuros estudios es importante proponer proyectos que tomen como actores principales a los sujetos en situación de desplazamiento, para lograr comprender el rol de la pedagogía en la identificación de problemáticas sociales, la búsqueda de la superación de las mismas y la erradicación de cualquier tipo de conductas violentas o discriminatorias cuestionando a su vez al contexto educativo sobre sus debilidades y fortalezas ante la forma de intervención sobre este tipo de situaciones, para así poder realizar un replanteamiento del quehacer docente en el que participe como sujeto activo la totalidad de la comunidad educativa.

\section{Referencias}

Acnur. (2003). La población desplazada por la violencia en Bogotá. Una responsabilidad de todos. Bogotá.

Acnur, Corporación Acción Legal y Universidad Pedagógica Nacional. (2004). Pedagogía y desplazamiento: 1er. Encuentro Nacional de experiencias con comunidades en situación de desplazamiento. Bogotá.

Albán, A. (2012). La educación intercultural ante el desplazamiento forzado: ¿posibilidad o quimera? Contexto, 1(1), 55-66.

Bello, E., Díaz, S. y Rincón, Y. (2016). Prácticas pedagógicas en contexto de conflicto armado. Quehaceres Normalistas, 4, 141-157.

Bisquerra, J. (2003). Relaciones interpersonales. México D. F.: McGraw Hill.

Bohoslavshy, R. (1986). Psicopatología del vínculo profesor-alumno: el profesor como agente socializante. México D. F.: El Caballito.

Centro Nacional de Memoria Histórica. (2015). Una nación desplazada. Informe Nacional de desplazamiento forzado en Colombia. Bogotá. Recuperado de http://www.centrodememoriahistorica.gov.co/descargas/informes2015/nacion-desplazada/una-nacion-desplazada.pdf

Contreras, A. y Contreras, M. (2012). Práctica pedagógica: postulados teóricos y fundamentos ontológicos y epistemológicos. Heurística: Revista digital de historia de la educación, 15, 197-220.

Correa de Andreis, A., Palacio, J., Jiménez, S. y Díaz, M. (2009). Desplazamiento interno forzado. Restablecimiento urbano e identidad social. Barranquilla: Ediciones Uninorte.

Díaz, C. y Sarmento, D. (2011). Currículo y prácticas pedagógicas. Voces y miradas con sentido crítico. Bogotá: Universidad de la Salle.

Giddens, A. (2007). Sociología. Madrid: Alianza. Jiménez, A. (2012). Infancia y conflicto armado, 1985-2006. En A. Jiménez, Infancia. Ruptura 
y discontinuidades de su historia en Colombia (pp. 127-157). Bogotá: Ecoe.

Kemmis, S. (2002). La teoría de la práctica educativa. En W. Carr, Una teoría para la educación. Hacia una investigación educativa crítica ( $p$. 17). Madrid: Morata.

OEl. (2009). Guía para la reflexión y valoración de prácticas inclusivas. Madrid: Organización de Estados Iberoamericanos para la Educación, la Ciencia y la Cultura (OEI). Recuperado de file://D:/Users/unesco5/Downloads/Guia.pdf

Pérez-Juste, R. (2010). Educación, ciudadanía y convivencia. Diversidad y sentido social de la educación. Bordón. Revista de Pedagogía, 59, 239-260.

Ramírez, A. (2014). La educación escolar como factor de inclusión social desde un planteamiento sistémico. El caso de la niñez jornalera migrante en los valles de Culiacán, Sinaloa (México). Barcelona: Universitat de Barcelona. Recuperado de http://www.tesisenred.net/bitstream/handle/10803/279213/AARI_TESIS.pdf

Restrepo, M. (1999). Escuela y desplazamiento. "Una propuesta pedagógica". Bogotá: Revolución Educativa Colombia Aprende. Ministerio de Educación Nacional. Recuperado de https://www.mineducacion.gov.co/cvn/1665/articles-129319_archivo_pdf.pdf

Rodríguez, G., Gil, J. y García, E. (1996). Metodología de la investigación cualitativa. Málaga: Aljibe.

Zuluaga, O. (1999). Pedagogía e historia. Bogotá: Anthropos. 